Jurnal Riset Sistem Informasi Dan Teknik Informatika (JURASIK)

Volume (4) Juli 2019, pp 34-40

ISSN: 2527-5771/EISSN: 2549-7839

http://tunasbangsa.ac.id/ejurnal/index.php/jurasik

\title{
Desain E-Commerce Rumah Hijab Boutique Berbasis Android
}

\author{
RD. Kusumanto, Mohammad Fadhli \\ Politeknik Negeri Sriwijaya \\ Jalan Srijaya Negara Bukit Besar Palembang \\ Userfadli61@gmail.com
}

\begin{abstract}
Muslim hijab clothes in today's era are increasingly in demand, especially Indonesian women, it is evident that more and more commercial and online figures sell Muslim hijab clothing which continues to grow every day because the interest of buyers also increases, but because many businessmen are interested in opening hijab Muslimah business in business increasingly stringent, it takes an innovation in product marketing in order to compete. ECoommerce design which is currently very popular is one of the strategies in marketing products by businessmen, E-Commerce utilizes technological developments such as websites and androids connected to the internet network. The use of technology like this can reach a wide range of marketing but with not so much capital, and extensive marketing can provide benefits for businessmen because they can increase sales turnover. The use of the website is very much applied by business people, but the use of websites and android can optimize product marketing, because android is an efficient mobile device that can be carried anywhere, so sales and purchases can be done anywhere.
\end{abstract}

Keywords: Innovation, E-Commerce, Websites, Androids.

\begin{abstract}
Abstrak
Pakaian hijab Muslimah pada era sekarang semakin banyak diminati, terkhusus perempuan indonesia, terbukti semakin banyak tokoh komersial maupun online yang menjual pakaian hijab Muslimah yang setiap harinya terus bertambah karna minat pembeli juga bertambah, namun karena banyaknya pembisnis yang berminat membuka usaha pakaian hijab Muslimah menjadikan persaingan dalam berbisnis semakin ketat, diperlukan suatu inovasi dalam pemasaran produk agar dapat bersaing. Desain E-Coommerce yang saat ini sangat populer menjadi salah satu strategi dalam memasarkan produk oleh pembisnis, E-Commerce memanfaatkan perkembangan teknologi seperti website dan android yang terhubung kejaringan internet. Pemanfaatan teknologi seperti ini dapat menjangkau pemasaran yang begitu luas tetapi dengan modal yang tidak begitu besar, serta pemasaran yang luas dapat memberikan keuntunngan bagi pembisnis karna dapat meningkatkan omset penjualan. Penggunaan website saja sudah sangat banyak diterapkan oleh pembisnis, namun penggunaan website dan android dapat mengoptimalkan pemasaran produk, karena android merupakan perangkat mobile yang efisien dan dapat dibawa kemana saja, sehingga penjualan dan pembelian dapat dilakukan dimana saja.
\end{abstract}

Kata Kunci : Inovasi, E-Commerce, Website, Android. 
Jurnal Riset Sistem Informasi Dan Teknik Informatika (JURASIK)

Volume (4) Juli 2019, pp 34-40

ISSN: 2527-5771/EISSN: 2549-7839

http://tunasbangsa.ac.id/ejurnal/index.php/jurasik

\section{PENDAHULUAN}

Bisnis dalam penjualan pakaian hijab Muslimah saat ini telah benar-benar mengalami transformasi, tidak hanya dipakai sebagai identitas keshalehan saja, namun juga telah menjadi trend mode di kalangan muslimah. Ditinjau dari segi ekonomi, trend ini melahirkan bisnis baru yang sangat prospektif [2]. Trend ini menjadi peluang bisnis yang besar, karna meningkatnya kemauan perempuan untuk menutup aurat, sehingga menjadikan bisnis baru ini sangat menjamin, namun seiring berjalannya waktu dan semkain berkembangnya mode style hijab yang terus mengeluarkan produk terbaru, dan menuntut pembisnis untuk siap bersaing dalam meningkatkan pemasaran agar produk dapat dikenal banyak masyarakat. Transaksi pembelian yang dapat dilakukan kapanpun dan dimanapun melalui E-commerce menjadi solusi dalam meningkatkan daya saing untuk memasarkan pproduk. Ecommerce merupakan kegiatan bisnis yang dilakukan secara online dengan bertujuan mengambil keuntungan penjualan, pembelian, serta pelayanan informasi dan perdagangan dengan memanfaatkan jaringan internet.

Kemampuan website atau internet yang mampu mengirimkan berbagai macam data seperti gambar, text, grafik, animasi, suara, bahkan video, maka banyak pembisnis yang memanfaatkan teknologi ini dengan membuat homepage dalam mempromosikan usahanya [1]. Perancangan E-Commerce berbasis website sudah banyak diterapkan oleh pembisnis online, pada penelitian ini akan mengembangkan E-Commerce berbasis website menjadi mobile phone yaitu android. Android merupakan sistem operasi terbaru dan sangat trend pada era teknologi sekarang ini, anroid memiliki kelebihan dibandingkan perangkat mobile lainnya. Android juga menggunakan sistem layar sentuh (touch screen) yang memberikan kemudahan bagi pelanggan dalam penanganan navigasi. Pada penelitian ini akan merancang Desain ECommerce berbasis android, yang mana Kemajuan teknologi pada bidang mobile ini memberikan banyak sekali keuntungan-keuntungan dan juga dapat memberikan kemudahan dalam pemasaran produk bagi pembisnis.

Pemasaran produk merupakan hubungan komunikasi antara penjual dan pembeli seperti promosi yang berupaya untuk memberitahukan atau menawarkan produk maupun jasa dengan tujuan menarik konsumen untuk membeli atau mengkonsumsinya[3]. Tujuan dalam penulisan ini adalah mengembangkan penelitian sebelumnya yang membahas mengenai desain E-Commerce yang berbasis web menjadi berbasis android. Adapun beberapa manfaat dari penelitian ini yaitu menjadi solusi bagi pembisnis untuk dapat memanfaatkan kemajuan teknologi dalam memasarkan produk, sehingga dapat memberikan keuntungan.

\section{METODOLOGI PENELITIAN}

Sebuah teknologi baru memiliki potensi yang besar dalam mengubah cara belajar untuk mendapatkan informasi yang lebih. Dalam penelitian ini pemanfaatan teknologi untuk dapat berinovasi dalam berbisnis melalui media mobile phone. 


\section{1 . Desain Penelitian}

Adapun desain penelitian adalah:

a. Metode Observasi

Metode yang dilakukan dengan cara pengamatan yang dilakukan penulis terhadap obyek yang hendak diteliti.

b. Studi Literatur

Dengan mempelajari buku-buku yang berkaitan dengan sistem sebagai referensi.

c. Analisis dan Perancangan sistem

Menganalisis algoritma yang berbasis interaktif

d. Implementasi/coding

Mengimplementasikan rancangan yang diinginkan kedalam bentuk program computer yang dibangun menggunakan PHP, MySQL, dan Xampp.

\section{HASIL DAN PEMBAHASAN}

Analisis sistem pada penelitian ini yaitu dengan cara merancang suatu sistem yang hendak dibangun sesuai kebutuhan yang dibutuhkan dalam menyampaikan informasi, sehingga sistem ini dapat berjalan sesuai dengan kebutuhkan yang diperlukan. Dan memastikan setiap sistem yang dibangun memberikan manfaat kemudahan baik untuk target penjual maupun pembeli.

Data yang dibutuhkan berupa data perancangan sistem berupa database, HTML, MySQL dan Xampp dalam perancangan sistem. Data tersebut dibangun menjadi sebuah program yang menghasilkan sistem sesuai kebutuhan untuk membangun suatu sistem selain mempersiapkan perancangan sistem juga dibuthkan komponenkomponen perangkat lunak dan perangkat kerasnya, sehingga menghasilkan sistem yang baik[4]. Sedangkan use case diagram memfasilitasi komunikasi interface. Berikut ini use case diagram yang dibuat pada perancangan sistem [5].

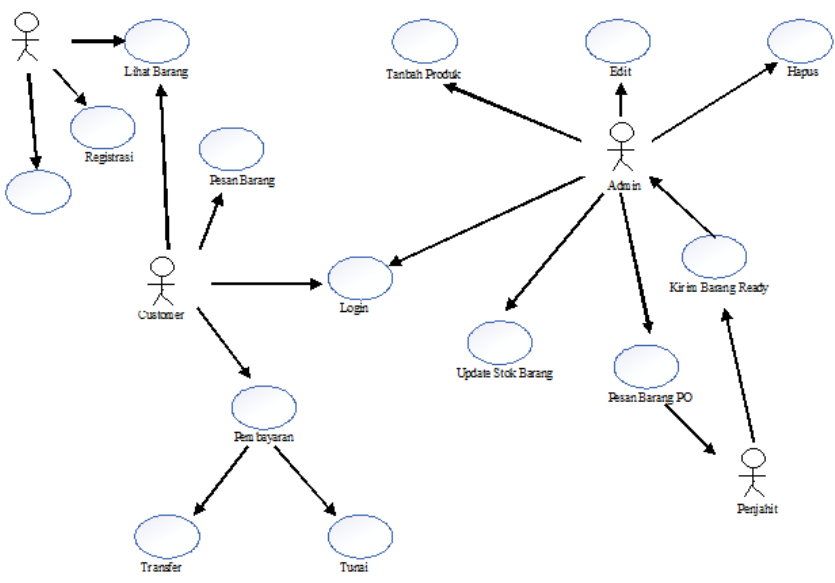

Gambar 1. Use Case 
Jurnal Riset Sistem Informasi Dan Teknik Informatika (JURASIK)

Volume (4) Juli 2019, pp 34-40

ISSN: 2527-5771/EISSN: 2549-7839

http://tunasbangsa.ac.id/ejurnal/index.php/jurasik

Implementasi perancangan sistem dibuat berdasarkan kebutuhan dan sesuai use case yang dibangun. Pada proses perancangan program sebelum merancang E-Commerce berbasis android sebelumnya membangun program website terlebih dahulu menggunakan Software Xampp, yang mana didalamnya memiliki fiture yang menyimpan database, serta pemograman coding menggunaka Notepad++, untuk melakukan operasi tersebut agar terhubung dengan jaringan internet maka diperlukan penghostingan link website. Langkah selanjutnya untuk membangun aplikasi yang berbasis android program yang sudah dibangun sebelumnya berbasis website, dan diteruskan menjadi android, diperlukan Software Android Studio untuk mengkonvert data program yang sebelumnya website menjadi android tanpa harus membangun program ulang.

Pada halaman pertama akan menampilkan desain beranda customer yang menampilkan semua katalog produk, namun untuk memesan produk customer perlu melakukan login jika Sudah memiliki email dan password, untuk masuk ke menu login cukup klik sub menu paling atas klik login. dapat dilihat pada tampilan seperti gambar 2:

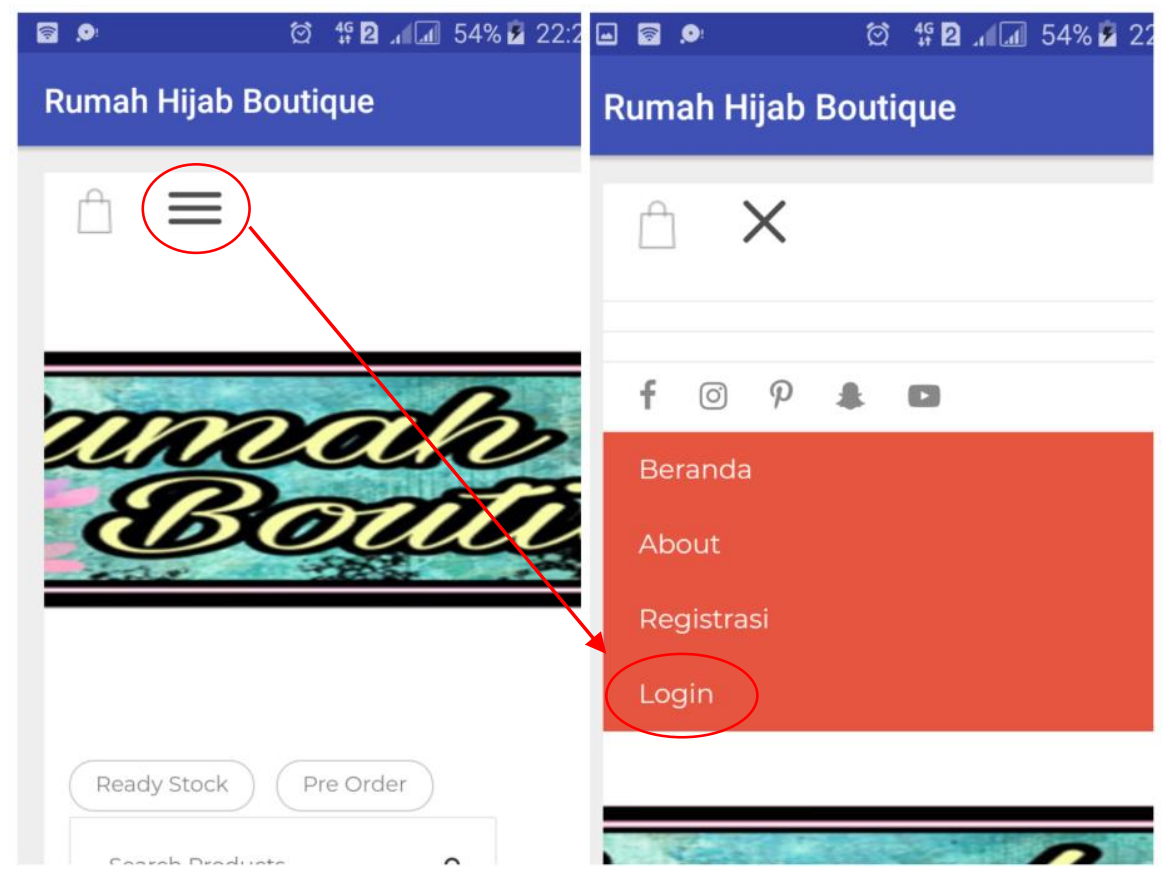

Gambar 2. Halaman Beranda Customers

Pada tampilan selanjutnya yaitu menu login, bagi customer yang Sudha melakukan registrasi tinggal masukan username berupa alamat email dan password, jika belum maka perlu melakukan registrasi, klik registrasi utk masuk ke tampilan registrasi, dapat dilihat pada tampilan seperti gambar 3 : 
Jurnal Riset Sistem Informasi Dan Teknik Informatika (JURASIK)

Volume (4) Juli 2019, pp 34-40

ISSN: 2527-5771/EISSN: 2549-7839

http://tunasbangsa.ac.id/ejurnal/index.php/jurasik

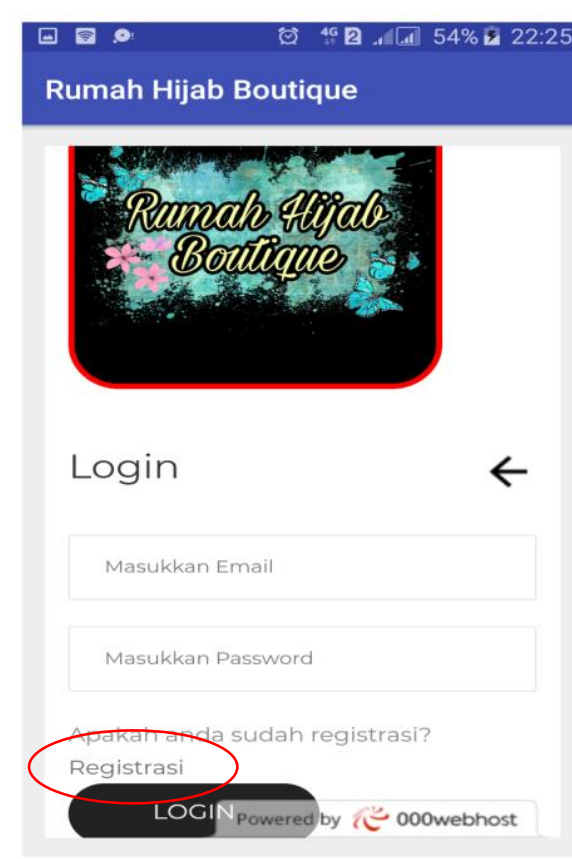

Gambar 3. Halaman Login

Pada tampilan desain registrasi menamppilkan colum yang harus diisi berupa informasi customer untuk keperluan data, serta mendapatkan username dan password untuk login, dapat dilihat pada tampilan seperti gambar 4 :

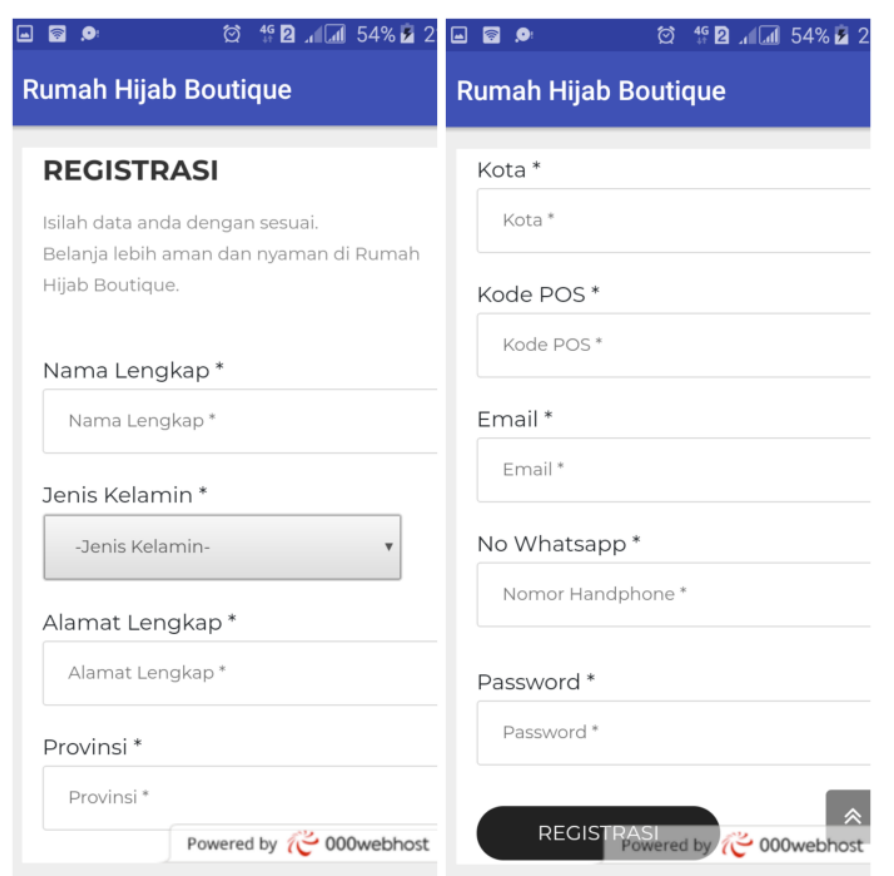

Gambar 4. Halaman Registrasi 
Tampilan selanjutnya yaitu tampilan dashboard pada admin, yang mana sebelumnya perlu juga melakukan login, namun bedanya username dan password untuk admin sudah terdaftar melalui program dan hanya memiliki satu admin pada tampilan ini memiliki bnayak submenu yaitu, pengolahan pesanan yang masuk, Stok barang, data customer, proses pengiriman, sampai dengan data barang selesai, dapat dilihat pada tampilan seperti gambar 5 :

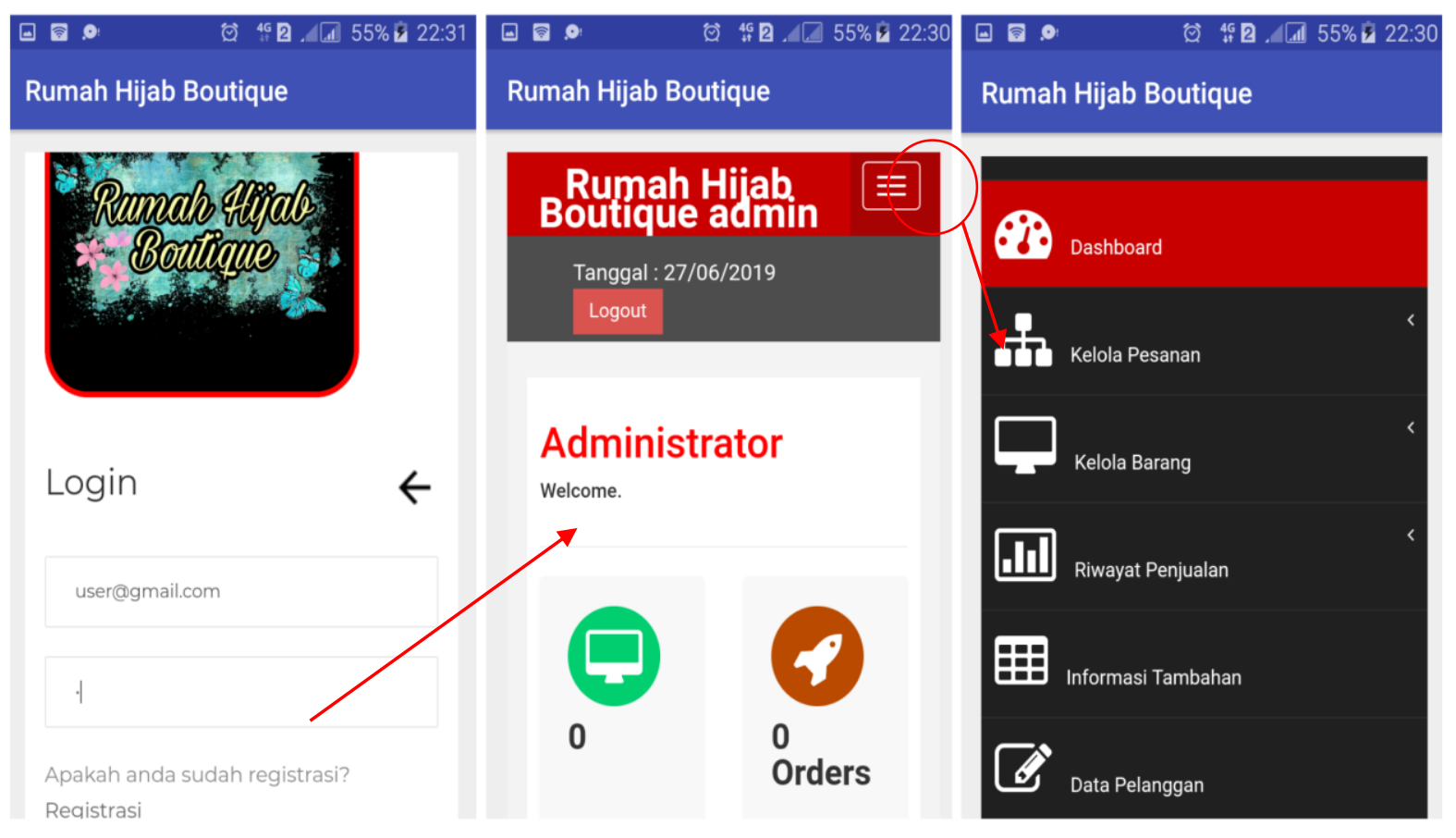

Gambar 5. Login Sebagai Admin

\section{SIMPULAN}

Berdasarkan hasil pembahasan yang telah diuraikan sebelumnya, maka penulis menyimpulkan :

a) Perancangan sistem E-Commerce sesuai kebutuhan, digambarkan menggunaka use case untuk mengetahui program sistem seperti apa yang hendak dibangun.

b) Perancangan sistem berbasis Web menggunakan Xampp, dan Notepad++ sebagi database dan Bahasa pemograman.

c) Sistem berbasis Androdi menggunakan Software Android Studio untuk menghasilkan aplikasi beruppa apk Android.

d) Melakukan penghostingan Link Website untuk dapat terhubung dan dapat di akses melaui internet.

e) Hasil akhir dari penelitian ini adalah sebuah aplikasi Android yang dikembangkan dari program sistem website sebelumnya. 
Jurnal Riset Sistem Informasi Dan Teknik Informatika (JURASIK)

Volume (4) Juli 2019, pp 34-40

ISSN: 2527-5771/EISSN: 2549-7839

http://tunasbangsa.ac.id/ejurnal/index.php/jurasik

\section{DAFTAR PUSTAKA}

[1] Bodendorf, Freimut and Florian Lang. 2009.Automated Services for Market-Based ECommerce Transactions. Proceedings of the International MultiConference of Engineers and Computer Scientists 2009 Vol I IMECS 2009, March 18 - 20, 2009, Hong Kong

[2] https://www.hidayatullah.com/artikel/ghazwul-fikr/read/2019/06/27/166839/hijab-dankomodifikasi-keshalehan-muslimah.html

[3] Firdaus, Septiana. 2012. Perancangan Aplikasi Multimedia Interaktif Company Profile Generic. ISSN : 2302-7339 Vol. 01 No. 092012.

[4] Andri, Gus. 2012. Strategi Pemasaran Dan Efektivitas Periklanan Dengan Menggunakan Metoda Komunikasi. Jurnal Manajemen dan Kewirausahaan. Volume 3, Nomor 2, Mei 2012, ISSN : 2086 5031

[5] Aripurnamayana, M.Irfan. 2011. Rancangan Dan Pembuatan Mobile Learning Berbasis Android. 